\title{
An Empirical Study Unfolding the Hiatus in Creating Awareness Regarding Green Products Among Retailers of Gujarat
}

\author{
Anjali Manglani and Tejas Dave* \\ Department of Business Administration and Commerce, School of Liberal Studies \\ Pandit Deendayal Energy University, Raisan, Gandhinagar, Gujarat, India \\ Corresponding author email: manglanianjali133@gmail.com
}

\section{ABSTRACT}

Retailers of any stream are holding a significant place as they are the key player of entire supply chain. A green product is a product which contains various environment friendly features in it. This study tries to explore retailers' awareness regarding same. The study is conducted among 30 retailers from different regions of Gujarat state. The sample for the study is collected by convenience random sampling with the help of a structured questionnaire. The study has tried to reveal the significance of awareness regarding green marketing practices and a green product among retailers and how this can contribute in spreading awareness further. The study explored various reasons behind unawareness and also it tries to present significant sources for spreading information. The results disclosed that only two sources of information are contributing significantly i.e. whole-seller/dealer and product label. Further they also disclosed their relationship with various features of a green product. To analyze the data frequency distribution, Weighted Average Mean and Oneway ANOVA is applied in the study. The study concluded by disclosing the importance awareness about green products and manufacturers' contribution in generating and spreading awareness among FMCG retailers as well as the entire down-stream of FMCG.

KEY WORDS: GREEN PRODUCTS, AWARENESS, RETAILERS.

\section{INTRODUCTION}

Retailers of any stream are holding a significant place as they are the key player of entire supply chain. A company's product is been mostly promoted by a retailer as they are the only stake holder that comes directly infront of consumers/customers for selling a company's product. Green marketing practices are those practices which are pursued by taking care of environment as the crucial base for performing any commercial activity right

Biosc Biotech Res Comm P-ISSN: 0974-6455 E-ISSN: 2321-4007

\section{crossef}

Identifiers and Pagination

Year: 2021 Vol: 14 No (5) Special Issue

Pages: 198-201

This is an open access article under Creative

Commons License Attribn 4.0 Intl (CC-BY).

DOI: $h t t p: / / d x$.doi.org/10.21786/bbrc/14.5/36 from manufacturing till disposal of a product's packaging. A green product is a product which contains various environmental features in it. This study tries to explore retailers' awareness regarding same. The study has tried to reveal the significance of awareness regarding green marketing practices and a green product among retailers and how this can contribute in spreading awareness further.

\section{Objectives}

1. To examine level of awareness among FMCG retailers with regard to Green products.

2. To identify the reason behind lack of awareness among FMCG retailers.

Review of Literature: Anna Siefken; Lindsey Gertler (2008) has tried to explore the trends among consumers regarding environment and retailers' perception; how 
efficiently energy consumption contributes in making retail green; case studies of green market players i.e. "Wal-Mart, The Home Depot, Best Buy and Amazon.com" and tried to explore the strategies that made retail green successfully. Dr. AnubhaVashisht; Dr. Bharti Wadhwa; Prof. AakanshaUppal (2013) has made an attempt to examine the level of awareness regarding green marketing among consumers and retailers. Also, study included consumer's attitude factors affecting buying behavior and certain key advices to promoters.

Dr.P.Mohanraj; Mr.S.Rajesh (2018) has derived the prospects pertaining to future scenario of retail industry with regard to green marketing practices. The study aimed to examine the demographic profile of green retailers of Erode district and to evaluate them with regard to green marketing. G.Deepalakshmi (2019) conducted a quantitative study to explore the awareness among retailers regarding green marketing and its significance on environment. This was a descriptive study conducted with the help of primary as well as secondary data. K.SathiyaPriya; ERB. PRATIKSHA (2019) has explored present and future scenario of green marketing with regard to manufacturers, retailers and consumers along with upcoming various challenges and future scope of growing in green marketing.

\section{RESEARCH METHODOLOGY}

To accomplish the research objectives the study is conducted among 30 retailers from various districts of Gujarat state. The data is collected through convenience random sampling with the help of a structured questionnaire is used as an instrument for collecting the data for the study.The study is analyzed by One way ANOVA for hypothesis testing, Weighted Average Mean and Frequency Distribution for representing significant data and figures. To pursue the analysis, Cronbach's alpha is determined to check the correlation among variables and reliability of the instrument. The value of Cronbach's alpha is determined as 0.883 which is highly significant.

\section{Hypothesis for the Study:}

Ha: Various sources of information are contributing significantly in creating awareness among retailers

Ha1: Awareness is having significant relation with various sources of information

Ha2: Various sources of information are contributing significantly in creating awareness regarding various features of a green product among retailers.

Analysis and Interpretation: The study is undertaken in Gujarat among 30 FMCG retailers. The study disclosed that out of 30 retailers, only 6 retailers are aware about green products and 24 retailers are unaware which is a huge number pertaining to sample size of the study. For increasing awareness among retailers, it is necessary to identify the significant source of information from which retailers are able to create awareness.

Researcher inquired from retailers regarding various sources which included 'News Papers, various periodicals or magazine, journals, labels on a product, e-commerce and social media portals, events such as conference or exhibitions, brochure of a respective company, respective company's website or advertisement and information generated via whole seller or a dealer'. The results disclosed that out of above all the means of generating information only two sources contributed significantly to retailers' awareness. From 6 aware retailers, majority of retailers gained knowledge about green products with the help only two sources of information i.e. 'a whole seller or dealer and from product's label'. To examine the significance of both the sources with retailers' awareness One-way ANOVA is applied. The results disclosed that both the sources of information i.e. a whole seller or dealer has significance value of 0.000 and product's label has significance value of 0.043 are having significant relation with awareness as the value is significance is below 0.05 .

Therefore, alternative hypothesis is accepted;Ha1: Awareness is having significant relation with various sources of information.

To explore the contribution of each of the two sources critically, One way ANOVA is applied between all the features of a green product and both the sources of awareness. A Green Product has following features along with their relation with relevant source of awareness.

The results disclosed that the Alternate Hypothesis is accepted; Ha2: Various sources of information are contributing significantly in creating awareness regarding various features of a green product among retailers.

Hence, the main alternate hypothesis is accepted i.e. Ha: Various sources of information are contributing significantly in creating awareness among retailers.

To examine the reason behind unawareness among retailers a question pertaining with Likert Scale was asked to retailers which consists of various reasons behind unawareness. To analyze the obtained responses weighted average mean is applied and the results are disclosed as below:

Poor Understanding about green marketing practices is the main reason which gained the maximum weight among all the reasons i.e. 7.666667 but rest all the 
reasons are also having significant weights relevant to the highest weight. That means all the above mentioned reasons are significantly responsible behind the unawareness among retailers.

Table 1. Features of a Green Product and their Sources of Information

Features of

a Green Product

\begin{tabular}{|c|c|}
\hline Product's & Whole- \\
Label & Seller/ \\
& Dealer \\
\hline
\end{tabular}

Use of renewable resources

in manufacturing a product

Energy (Electricity Power)

efficient manufacturing

Water efficient

manufacturing practices

Less pollution from manufacturing practices (reduced C02/GHG emissions)

Minimum waste from manufacturing

process/ Efficient waste management

Products are not tested on animals

(this can be known with the help of label on product)

Packaging is biodegradable/compostable

(this can be known with the help of label on product)

ISO Certificate for environment (e.g. ISO 14001, etc.)

this can be known with the help of label on product

Type of Plastic is recyclable or reusable

or both or recoverable (this can be known with

the help of label on product)

Any other green label (e.g. Green dot) except

labels mentioned above

Use of renewable energy in manufacturing

a product such as biomass, bio fuel,

Agro waste, PNG, etc. fossil fuel.

Eco friendly logistics

Findings and Implications of the Study: Retailers are the significant stakeholders in a supply chain. Also, retailers are the only stakeholders that come directly in contact with the main consumers. Retailers can play a vital role in spreading awareness about green marketing practices among consumers as well as whole sellers and dealers. As retailer is the common factor between both the stake holders. Therefore it is necessary to make retailers aware about green products. Here, the study disclosed that very few retailers are aware regarding green products, the reasons behind their unawareness and there are only two main sources of information contributing significantly in creating awareness among retailers.

To make maximum retailers aware it is required to utilize all the salient sources of spreading information actively by manufacturers. As a whole seller deals with multiple retailers as well as a retailer deals with multiple whole sellers, a spread of green information becomes easy if manufacturing company participates in spreading awareness among them. The down-stream supply chain of FMCG products can contribute in supply of products as well as supply of salient information about green products associated with respective company. This will result not only in increased awareness among retailers but will also help to spread awareness among entire supply chain stake holders.

Limitations and Scope of the Sudy: This study is limited in between 30 retailers within Gujarat state. To gain more precise reasons behind unawareness and to explore more sources for spreading the information, a more detailed study among a bigger sample size of retailers. Also, this can be conducted within entire down-stream to gain a meaning full and significant insight towards awareness of green products. 


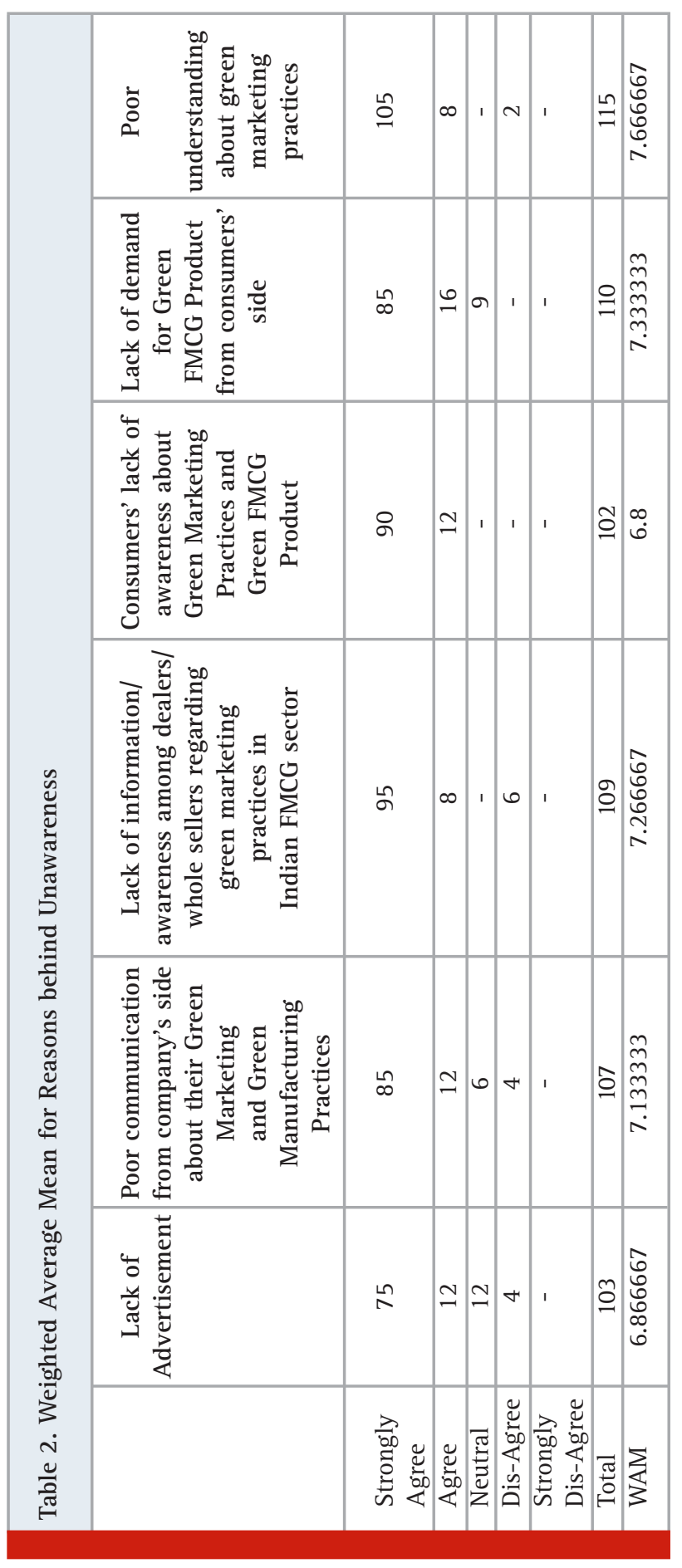

\section{REFERENCES}

Deepalakshmi, G. (2019). Awareness of Green Marketing in Retailing and its Impact in Environment. International Journal of Innovative Technology and Exploring Engineering (IJITEE), 9(2S3), 440-444.

Dr.P.Mohanraj, \&t Mr.S.Rajesh. (2018). A Study On Impact Of Retailing In Green Marketing In Erode District. International Journal of Business and Management Invention (IJBMI), 7(9 Ver.1), 18-22.

Dr.AnubhaVashisht*, D. P. (2013). Study on Awareness Level of Retailers as Well as Consumers Towards Green Marketing. SSRN Electronic Journal, 1-12.

PRIYA, K., \& ERB.PRATIKSHA. (2019). A Study on Green Marketing in Retail Industry with Special Reference to Coimbatore City. International Journal for Research in Engineering Application \& Management (IJREAM), 4(10), 675-682.

Siefken, A., \& Gertler, L. (2008). The Greening of Retail-Opportunities for Increased Retail Engagement on Energy Efficiency. ACEEE Summer Study on Energy Efficiency in Buildings, 260-273. 